\title{
More than meets the eye: a longitudinal analysis of climate change imagery in the print media
}

\section{Saffron $\mathbf{O}^{\prime}$ Neill $^{1}$}

Received: 23 August 2018 / Accepted: 19 July 2019/Published online: 27 August 2019

(C) The Author(s) 2019

\begin{abstract}
Images are ubiquitous in everyday life. They are a key part of the communication process, shaping peoples' attitudes and policy preferences on climate change. Images which have come to dominate visual portrayals of climate change (and conversely, those that are marginalised or excluded) influence how we interact with climate change in our everyday lives. This paper presents the first in-depth, cross-cultural and longitudinal study of climate change visual discourse. It examines over a thousand images associated with articles about climate change in UK and US newspapers between 2001 and 2009, a pivotal decade for climate change engagement. Content, frame and iconographic analyses reveal a remarkably consistent visual discourse in the UK and US newspapers. The longitudinal analysis shows how the visual representation of climate changed mid-decade. Before 2005, a distancing frame was common. Imagery of polar landscapes acted as a visual synecdoche for distant climate risk. After 2005, there was a rapid increase in visual coverage, an increase in use of the contested visual frame, alongside an increase in climate cartoons, protest imagery and visual synecdoches. These synecdoches began to be subverted and parodied, particularly in the right-leaning press. These results illustrate the rise of climate change scepticism during the mid-2000s. This study has implications for public engagement with climate change. It shows that the contested and distancing visual frames are deeply and historically embedded in the meaning-making of climate change. Additionally, it showcases the importance of visual synecdoches, used by newspapers in particular circumstances to engage particular audiences. Knowing and understanding visual use is imperative to enable an evidence-based approach to climate engagement endeavours.
\end{abstract}

This article is part of the Special Issue on 'Everyday Climate Cultures: Understanding the cultural politics of climate change' edited by Goodman, Doyle and Farrell

Saffron O’Neill

s.oneill@exeter.ac.uk

1 Geography, College of Life and Environmental Sciences, University of Exeter, Amory Building, Rennes Drive, Exeter EX4 4RJ, UK 


\section{Introduction}

The IPCC argues that sustainable consumption can be "viewed in the broader context of lifestyles and everyday life' (IPCC 2014: 308). Yet, the report says little about how everyday cultures and practices of sustainability are discussed, debated or contested. The media (whether that is newspapers, TV, radio or online and social media) play a key role in this performance of everyday life. Media coverage also reflects something of the state of societal consciousness on an issue at a particular point in time. Media coverage shapes how people talk, think about and act on everyday practices of sustainability (Smith 2017). It acts as a central agent for raising awareness and disseminating information, and offers a forum through which climate governance can be discussed and legitimised (Schmidt et al. 2013). This is a negotiated process: it is not that audiences consume media passively, but that media outlets offer an array of interpretative packages which audiences use in order to conceptualise an issue (Gamson and Modigliani 1989). Media act as important gatekeepers, helping to set the boundaries of an issue, and to legitimise (or sideline) particular actors within a debate. Media coverage of climate change does not then determine how people engage with the issue, but it does shape the possibilities for engagement (Carvalho and Burgess 2005).

\subsection{Media, issue attention and framing}

This paper uses the two theoretical concepts of issue attention and framing to interrogate longitudinal trends of climate visuals in the media. Issue attention refers to how much coverage a topic receives in the media. The amount of coverage of an issue is necessarily limited by the format of the media; for example, the number of pages in a newspaper, or minutes available for a TV broadcast (Schäfer et al. 2014). An increase in issue attention makes a topic more salient in peoples' minds. Conversely, if media attention to an issue wanes, peoples' engagement is decreased. Downs (1972) first posited that issue attention was cyclical, with several distinct stages taking an issue from obscurity, catapulting it to public concern, then an inevitable decline in attention once the media's appetite for novelty and drama had been exhausted. This original work has been enriched by subsequent scholars (e.g. Nisbet and Huge 2006), who argue that particular media environments (particularly, the shift in coverage across news beats, from specialist science journalists to political writers) and the role of other actors (scientific institutions, NGOs, political institutions) are key for understanding how issue attention waxes and wanes across time. Studies have investigated how the issue-attention cycle plays out for the climate change issue, showing the importance of narratives for maintaining issue cycle trajectories (McComas and Shanahan 1999), examining different media sources (cross-culturally, Brossard et al. 2004; across social media, Lörcher and Neverla 2015), empirically demonstrating how public awareness of climate change is increased when climate change received a high level of issue attention in the mass media (Sampei and Aoyagi-Usui 2009) and illuminating how the cycle plays out in practice with insights from journalists (Farrow 2000).

Media framing is defined here following Entman (1993:52): 'selecting some aspects of a perceived reality and making them more salient in a communicating text, in such a way as to promote a particular problem definition, causal interpretation, moral evaluation, and/or treatment recommendation'. Again, partly as a function of the limited space for communication within a media item - but also as a consequence of ideology, the social and professional routines of journalists, journalistic norms and the influence of pressure groups and elitessome aspects of reality are emphasised, whilst others are de-emphasised (Entman 1993). 
Depending on peoples' pre-existing attitudes and their previous conceptions of the issue, some frames will be more likely to resonate than others, reinforcing and influencing opinions on an issue. If particular frames become dominant and unchallenged, they can limit the participation of particular actors, affect the amount of media coverage, influence public opinion and ultimately even impact regulatory options (Nisbet and Huge 2006). For example, Singh and Swanson (2017) found that how climate change is framed can shape attitudes towards the issue, particularly for those on the political right. Framing is fundamentally about understanding how the communications process necessitates some aspects of an issue being emphasised, and made more salient (Entman 1993), at the expense of others. See Schäfer and O'Neill (2017) for a full review of how climate change researchers have utilised the concept of framing.

However, what is common to all the scholarly climate change issue attention research, and most of the framing work, is that it focuses on text only - completely disregarding any visual imagery within a media item. This neglect has led scholars in diverse areas to call for more research into the visual dimensions of climate communication (O'Neill and Smith 2014; Pearce et al. 2018). A lack of visual research is not limited to the issue of climate change. This situation is broadly indicative of the state of social science research as a whole, wheredespite the central role of imagery in the communication process - research examining visual representations is rare (Rose 2012).

\subsection{Media and imagery}

Understanding imagery in the news media environment is important for a number of reasons. First, images are often colourful, vivid and emotive (Joffe 2008). Whereas words and numbers require the use of the rational processing system (which is analytical, logical and deliberative), images allow for information processing using the experiential processing system (which is holistic, intuitive and affective; Epstein 1994). This means climate change imagery can be processed quickly, and help readers to navigate potential risks effectively (Leiserowitz 2006). Second, images draw readers into engaging with a media item, and help people in remembering information (Graber 1990). Third, images appear to prompt readers to both engage more deeply with that particular news item and to 'carry over' those considerations in thinking about related issues (Domke et al. 2002). Last, provided that readers share cultural references, images can transcend linguistic or geographic barriers in communicating information to audiences (Popp and Mendelson 2010).

Of course, the selection of which image accompanies a media item is not arbitrary, but instead is a product of both journalistic and editorial decision making. Photographs hold particular power as they are indexical, i.e. people view them uncritically, as they are considered to directly represent reality, rather than as a particular representation of reality (Messaris and Abraham 2001). Also, because visuals lack an explicit propositional syntax (causality is implied rather than stated, and causality relies on the reader making sense of implicit meanings), they can contain subtle references or clues which can promote views (e.g. ideological or racist undertones; Coleman 2010) in a way in which would not be acceptable in text.

Thus, the whole process of visual framing is highly ideological (Hall 1973), where images do not portray an objective reality (Urry 1992) but instead are normative cultural objects communicating a particular way of understanding an issue. The repetition and normalisation of particular images or image types and the converse, i.e. the absence of particular images or image types - is therefore political, in that it empowers particular voices and promotes particular ways of conceptualising climate change, whilst disempowering others and 
marginalising others (O’Neill 2013). Visual representations are therefore an important, yet under-explored cultural artefact of the everyday politics of climate change.

\subsection{Images for engagement}

In terms of climate change research, images have been shown to impact not only how people feel, but also how they act on climate change (Leiserowitz 2006). International comparative work (O'Neill et al. 2013; Metag et al. 2016) shows that particular types of images consistently invoke similar emotional responses. Imagery does not only impact how people engage with the media. The availability of compelling imagery also shapes the types of media narratives that are offered in the first place. For example, the availability of compelling imagery is a key factor in driving media coverage of climate change (O'Neill et al. 2015).

Several studies have examined climate visual imagery in mass media. The first studies to emerge in this area where rich in detail, documenting the social construction of climate change through imagery in specific media sources (National Geographic Magazine; Remillard 2011) or by specific actors (Greenpeace; Doyle 2007). Authors then sought to quantify the types of particular images in mass media sources (Smith and Joffe 2009; DiFrancesco and Young 2011; León and Erviti 2013; Nerlich and Jaspal 2014). Subsequently, studies have increased the timespan examined, the diversity of sources, the quantity of imagery examined and the strength of analysis (O’Neill 2013; Rebich-Hespanha et al. 2015; Wozniak et al. 2015; Born (2018); Pearce et al. 2018). These studies indicate that there is currently a dominant visual discourse associated with climate change in the media, at least in Western nations examined to date.

Despite this nascent work though, there are still significant gaps in knowledge on visual representations of climate change. In particular, there is a lack of work investigating how the visual discourse has evolved over long periods, rather than just as snapshots in time, and what this means for performing everyday practices of sustainability within the cultural politics of climate change. For the first time, this paper seeks to understand which imagery and visual frames dominate (and are marginalised) over long periods, whether key focussing events such as IPCC reports change the visual discourse, and how iconic climate imagery has changed over time. This paper draws on the methodology developed in O'Neill (2013), which examined climate change visual framing in 13 newspapers during 2010. O’Neill (2013) found two distinct and prominent visual frames (the 'distancing' and 'politicised/contested' frames). This paper sets out to examine the historical trajectory of these two frames. This analysis contributes to this journal Special Issue by shedding light on how the media play a key role in the adoption or rejection of more sustainable everyday climate cultures.

\section{Method}

Images are defined as the concrete visual content elements within a media item (Wozniak et al. 2015). A two-country study was designed in order to compare and contrast nations with similar levels of public knowledge of climate change and comparable news media ecosystems. Both the UK and USA are active in the climate policy arena, and have influential contrarian voices. The analysis focussed on five newspapers, three UK-based (Daily Mail, Telegraph, Guardian) and two US-based (New York Times, Wall Street Journal). Several of these newspapers are notable for their reach. The Daily Mail, Guardian and New York Times are globally leading media reaching significant target populations well beyond their 'home' audiences (e.g. Schmidt 
et al. 2013). Notably, the Guardian is the most prolific legacy media outlet for climate coverage worldwide (Andrews et al. 2015). The newspapers have different ideologies (right- to leftleaning). All newspapers were available on microfilm at the British Library.

The period 2001-2009 was a pivotal decade for climate change engagement in these two nations. Climate change became embedded in public consciousness, and there was an upswing in levels of scepticism (Capstick et al. 2015) which still continue to hamper efforts to address the issue a decade further on. In terms of media attention, the start of the 2000s saw low levels of coverage, then a clear upwards shift from mid-decade on (see also Schmidt et al. 2013; Boykoff and Boykoff 2007). The timeframe for analysis was bookended by the IPCC Third Assessment Report in 2001, and at the end of the decade by the 2010 newspaper analysis of O’Neill (2013).

\subsection{Building the visual library}

Media researchers have easy access to large searchable databases (e.g. Nexis) which is a major reason why there is a proliferation of research on textual analysis of climate change media. Although Rebich-Hespanha et al. (2015) relied on the search function of such databases to define their image sample, pilot testing showed this to be unreliable here (for example, testing of the 'graphic' search function within Nexis, and then finding these stories on microfilm showed that Nexis both missed stories which did have an image, and it falsely claimed that stories had associated images where they did not). Thus, in order to build a full and accurate representation of images associated with climate change stories, a painstaking method involving both a news database search, then accessing relevant articles on archival microfilm, was used. The difficulty and time-consuming nature of constructing a rigorous and reliable visual data archive is a major reason why visual analysis is rarely undertaken.

First, following similar text-based analyses, a list of all articles from 2001 to 2009 containing three or more mentions of the terms 'climate change' or 'global warming' was generated using Nexis. A hardcopy of each article was then accessed via microfilm at the British Newspaper Archives at Colindale. Considerable difficulty was encountered with this process, including delays with accessing microfilms from deep storage, and in printing large volumes of data from the archives. Categorising errors within the archives meant that it was not possible to include the Sunday Mail or Sunday Telegraph publications; and that supplements to the main newspaper were sometimes not available, particularly in the case of the New York Times. Notwithstanding these constraints, each of the results from the Nexis list was accessed to check for associated visuals, then skim read for relevance. If both these checks were passed, a photocopy was made of the newspaper item. This resulted in a dataset of almost 5000 articles with associated images $(n=4971)$. As there were large differences in the number of articles per newspaper outlet, the data was sampled in order to give numbers of articles for each newspaper of at least a similar order of magnitude (Table 1). Following similar studies (e.g. Boykoff and Mansfield 2008), these were then sampled chronologically by selecting the first of each $\mathrm{X}$ articles (for example, one in every three articles for the Guardian), starting from the first article published in 2001, in order to maintain the temporal pattern of data (final sample $n=1278$ ).

\subsection{Image analysis}

This paper builds on the methodology developed in O’Neill (2013) for climate visual analysis. Visual content analysis was used to describe the image corpus. Images were examined for their 
Table 1 Sampling method for the five newspapers

\begin{tabular}{llll}
\hline & Total image count & Sampling method & Final image sample \\
\hline Daily Mail & 169 & None & $(169)$ \\
Telegraph & 268 & None & $(268)$ \\
Guardian & 2856 & 1 in every 3 & 314 \\
New York Times & 1114 & 1 in every 2 & 279 \\
Wall Street Journal & 564 & 2 of every 3 & 248 \\
\hline
\end{tabular}

denotative content, or 'literal' meaning (Dyer 1982). This provides 'a background 'map' of a domain of visual representation' (Bell 2001:27). Major visual themes drew on the coding schema in O'Neill (2013) and included the following: people, causes (or more precisely, sources of GHG emissions), climate impacts, solutions (adaptation or mitigation options), science \& technology (including scientific diagrams) and protest. Each of these overarching themes contained a detailed breakdown of image theme sub-types. For example, for the 'people' theme, the sub-themes included politicians, scientists, business representatives and celebrities. This allowed an overview of which imagery is given prominence, and which is little used or missing. Each image was single coded. Pilot testing revealed the coding scheme to be stable, with a sub-sample of the dataset estimating an inter-coder reliability of $95.2 \%$ (Cohen's Kappa coefficient).

Then, representative images were placed in broader socio-political context. It did this through examining both the connotative content (how these objects relate to culture; structures of meaning which elucidate other, additional and implied meanings) and the ideological content (how a viewer explains how this intrinsic meaning comes to be, revealing underlying attitudes) of images (see Dyer 1982). It also drew on the positioning provided by article titles and image captions, as they help to place the viewer in relationship with the image (Hall 1973). These analyses were set in their socio-political context on synchronic (simultaneous depictions in multiple newspapers) and historical-diachronic (sequences across time, or issue evolution) axes (Carvalho and Burgess 2005). Results from the visual content analysis are then brought together and used alongside the in-depth reading of individual typical images in order to discuss visual framing of climate change in newspapers.

The following research questions are addressed:

1. Has the quantity and type of visual coverage of climate change changed over time?

2. Has there been stability or change in iconic climate imagery (polar bears, ice images, smokestacks; cf. O’Neill 2013)?

3. Which visual frames are used to portray climate change, and does this change over time?

\section{Results}

The results section examines each of the research questions in turn.

\subsection{Visual coverage over time}

Visual coverage gradually increased during the period 2001-2004. From 2004 to 2007, there was a rapid increase in climate visuals. Image quantity was only affected by socio-political 
events towards the latter end of the decade: earlier in the decade, the annual COPs and the IPCC TAR (2001) did not affect the quantity of visual images in newspapers. However, later on in the decade, coverage around the 2007 IPCC AR4 did produce a peak in visuals, as did the timing of the 2009 COP (COP15) and the co-occuring 'Climategate' affair.

Between 8 and $18 \%$ of all climate news stories in UK newspapers have an associated image, with the US newspapers figure slightly higher at between 10 and $21 \%$. Note these figures are certainly a (possibly considerable) under-representation of the number articles with associated visuals, as it compares this visual dataset (where articles are individually read, and only those substantively about climate change are counted) with the Boykoff et al. (2019) newspaper coverage figures (an automatic count of all articles mentioning climate change). Bearing this caveat in mind, it is estimated that at least one in every five articles about climate change has an associated visual.

In all newspapers, three visual domains (images of identifiable people, climate impacts and causes of climate change) dominate the climate change visual imagery coverage (range 45-76\%, mean 62\%). As O'Neill (2013) found, the 'people' domain was dominated by images of politicians (range 11-19\%, mean 16\%). Scientists, business leaders, celebrities and other identifiable individuals all comprised, on average, 3\% or less of coverage. Impacts imagery is particularly dominant in the UK newspapers (Telegraph 41\%, Daily Mail 34\%, Guardian 27\%). There is considerable diversity within the 'impacts' domain, although much of the coverage is of polar and ice imagery, species and landscapes at risk and drought or flooding. Images of 'solutions' comprise a small proportion of coverage (range 4-12\%, mean 9\%), much of which depicts non-fossil fuel transport (such as electric cars) and wind power. Similarly, scientific figures (such as maps, charts and infographics) are fairly uncommon, except in the Wall Street Journal where they comprise almost a third (29\%) of visual coverage. Climate change cartoons are present in each of the newspapers studied (range 3-12\%, mean 6\%). Images of climate protest are present in four of the five newspapers, at low levels (none in the Daily Mail; range $2-6 \%$, mean $4 \%$, in the other four newspapers).

These broad visual domains were also analysed for changes over time. Note that percentage of annual coverage - rather than article counts - is used, to account for the substantial increase in volume of visuals towards the end of the decade. However, this does mean that in the early part of the decade, low overall numbers of visuals mean that individual image counts have a disproportionate effect on the appearance of trends. There are four discernible trends over time. First, there is an increase in visuals depicting identifiable people over the decade (Fig. 1(a)). As discussed, much of this coverage is of politicians; and so coverage of politicians is low at the start of the decade (especially in 2003), but from 2005 onwards all newspapers used images of politicians to visualise climate change. Second, the coverage of 'solutions' also increases steadily, from almost no such images in 2001-2002 to 13\% of the total annual coverage by the end of the decade (Fig. 1(b)). Third, there is a decline in the use of impacts imagery over the decade. This is especially noticeable in the UK newspapers (particularly the Telegraph and Guardian), when as much as half of their coverage before mid-decade depicted climate change impacts (Fig. 1(d)).

Fourth, there is an increase in diversity in the visual discourse around mid-decade. Before 2005, climate change rarely featured in cartoons associated with articles (and never in the cartoons of the Telegraph or the Daily Mail; Fig. 4h). After, climate change cartoons associated with articles featured at fairly consistent levels (median 6-7\% from 2005 to 2009 inclusive) in all newspapers. Similarly, protest visuals rarely featured before 2005 (indeed, 2003 and 2004 

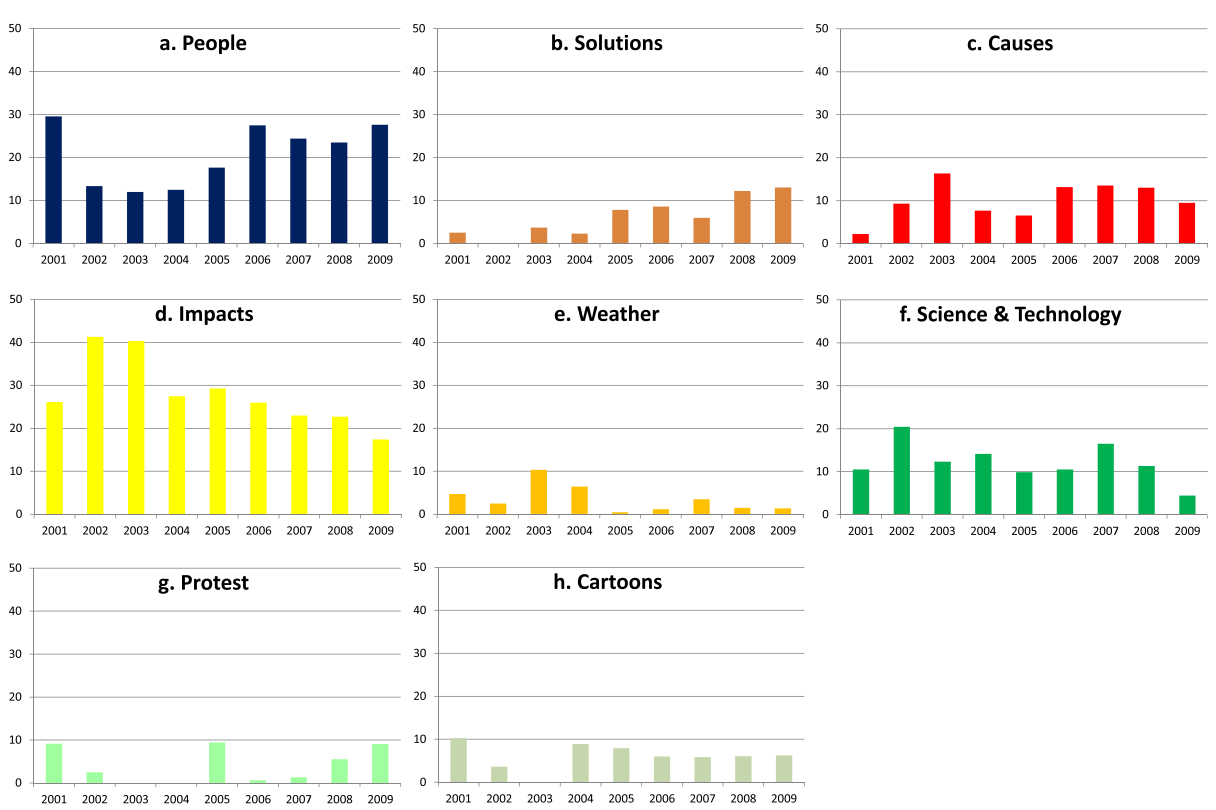

Fig. $1 \mathrm{a}-\mathrm{h}$ Percentage of total annual coverage in each of the visual domains over time (2001-2009), as an average of the five newspapers. Y axis is the percentage of annual newspaper coverage (to 50\%). Note this figure shows only major visual themes, so annual totals do not total $100 \%$.

saw no such images). From 2005, and particularly towards the end of the decade, protest images featured in all newspapers, and become a mainstay in the UK newspapers; Fig. 4g.

\subsection{Iconic imagery and climate synecdoches}

As the visual language of climate change evolved through the decade, so too do particular iconic images start to become more frequently used, and become embedded in the visual
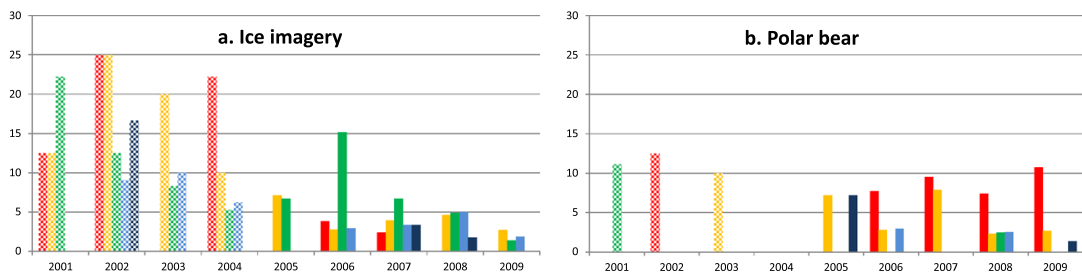

- Daily Mail

welegraph

- Guardian
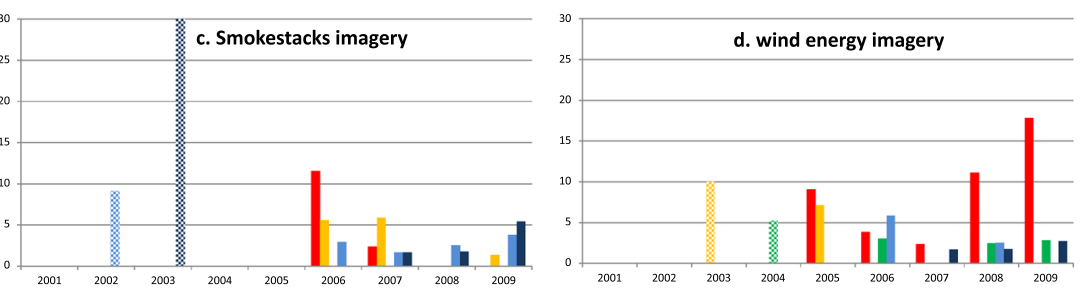

NYT

-WSJ

Fig. 2 a-d Percentage of total annual newspaper coverage for visual synecdoches, by newspaper (to 30\%). Totals before 2005 are light shaded, as the low numbers of visuals can have a disproportionate effect on the appearance of trends 
discourse. These have been termed 'visual synecdoches'. Visual synecdoches are a type of visual shorthand, used within a particular culture to immediately signify to the reader a particular set of ideas about climate change beyond the immediately represented denotative content (O’Neill 2013; O'Neill et al. 2015; see also Nerlich 2019). As these synecdoches become embedded in the visual discourse, they can become clichéd or stereotyped. As Linder (2006) described in his study of climate change advertising, visual synecdoches may also become subject to parody, inverting and challenging the original reading of the visual. Here, visual synecdoches were identified both through a bottom-up process, examining the dataset for frequently used imagery that was not directly associated with the manifest content of the text, and top-down, examining the dataset for iconic climate change imagery as identified in previous studies (including Smith and Joffe 2009, DiFrancesco and Young 2011, O’Neill 2013, León and Erviti 2013, Nerlich and Jaspal 2014, Rebich-Hespanha et al. 2015, Wozniak et al. 2015 and Born 2018). Notable visual synecdoches arising within this dataset are ice imagery and polar bears, smokestacks and wind turbines (Fig. 2).

Ice imagery (Fig. 2(a). and Fig. 3) comprises a considerable proportion of coverage across all newspapers. For example, it reaches as much as $25 \%$ of annual coverage for the Daily Mail and Telegraph in 2002. Ice imagery usage begins to decline (as a percentage of annual coverage) from around 2005 onwards. This ice imagery is beautiful and aweinspiring, and rarely depicts people. Analysis of the images, together with the articles' headlines, main text and caption shows how this visual synecdoche works to create feelings of distant wonder and threat of climate risk (see O'Neill et al. 2013) For example, the image alongside a 2002 Daily Mail piece titled 'The ice monster: fears as a 50 billionton Antarctic mass collapses' portrays a massive polar ice edge, devoid of any people or animals, with a caption describing the 'staggering' ice mass.

In contrast, imagery of polar bears is sporadic before 2005 and increases thereafter (Fig. 2(b) and Fig. 4). Polar bear imagery is more common in the Daily Mail and Telegraph but rarely seen in the other newspapers. Until 2007, polar bear images accompany straightforward reporting about the threat of climate change to the species. A typical

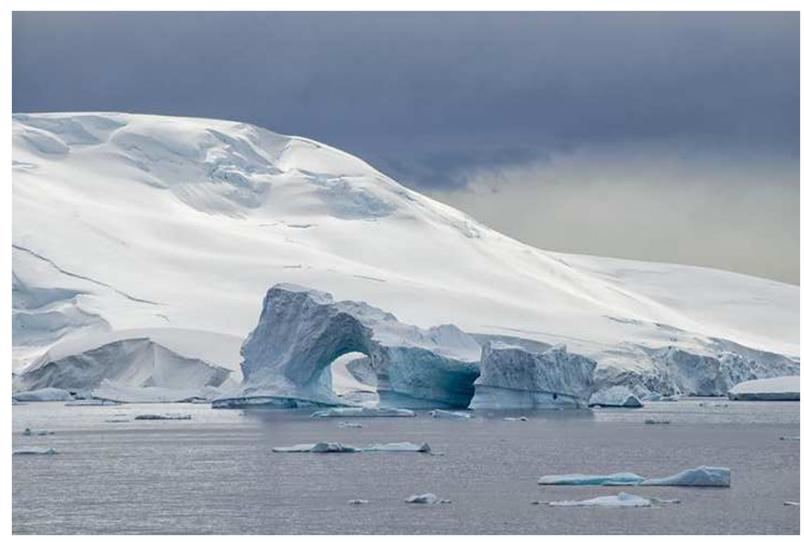

Fig. 3 A typical 'ice imagery' visual (note this image is not from the dataset, but is a Creative Commons licenced image used to illustrate the themes discussed). 'The crystal desert' by Christopher. Michel is licenced under CC BY 2.0 
Fig. 4 'Polar Meltdown' image.

Copyright Arne Naevra,

Naturbilder.no.

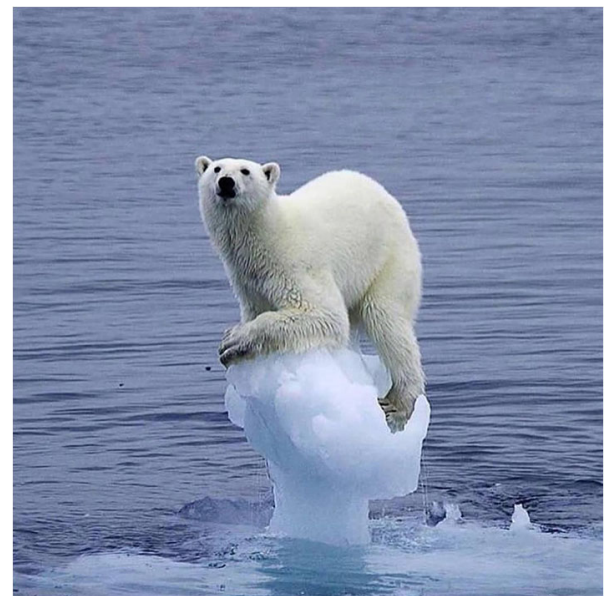

example is 'Polar bears in peril as Arctic ice cap melts' in the Daily Mail in 2002, picturing a lone bear in close-up. A similar piece in the Telegraph in 2003 pictures two polar bears on ice floes separated by dark water. This visual trope changes from 2007 onwards, when it starts to be subverted, and the polar bear icon is instead used to parody climate change. The Daily Mail articles 'Don't panic (much)' in 2008, and '10 mad ways to save the planet' (2009) are both illustrated with the same photograph. Arnae Nævra's awardwinning 'Polar Meltdown' image depicts a single bear scrabbling to cling onto a small ice floe floating in a dark sea. Similarly, in the Telegraph in 2007, the piece 'Don't look now: James Delingpole is terrified by our susceptibility to doomsday scenarios' is illustrated by a headshot of a winking polar bear captioned 'sceptical: a polar bear weighing up the evidence for climate change'. In contrast, the widespread recognition of the polar bear as a 'tired and hackneyed icon'-a (subverted) synecdoche-led to The Guardian avoiding such imagery where possible (Leo Hickman, former Guardian journalist, pers. comm., 13/07/18). As with O'Neill's (2013) study of newspaper imagery during 2010, polar bear images are rare in the US newspapers throughout the period.

Smokestacks imagery (Fig. 2(c) and Fig. 5) is almost non-existent before 2006 (used just three times, in US newspapers only). Then, in 2006, both UK and US newspapers start to use smokestacks imagery. This may well be as a consequence of the film An Inconvenient Truth, which launched in 2006 featuring a stylised smokestack-cyclone graphic as its cover image. It remains a small but regular part of the visual coverage from then on, in both US and UK newspapers. This imagery typically features dark-coloured scenes of industry, with towering chimneys billowing ominous clouds over the scene, sometimes featuring red or orange tones; together, these elements evoke feelings of heat, threat and danger (see O'Neill et al. 2013). Such images are used as ways to illustrate satirical messages, playing on the images' portrayal of fear and gloom ('Why the doom mongers have got it so wrong', Daily Mail 2006) and as a visual metaphor for lies and exaggeration ('Hot issue or hot air?' Telegraph 2007).

There is very little coverage of mitigation measures. However, there is evidence of images of wind turbines assuming visual synecdoche status. Wind turbine imagery consistently appears in the dataset from 2005 onwards (Fig. 2(d) and Fig. 6). It is 


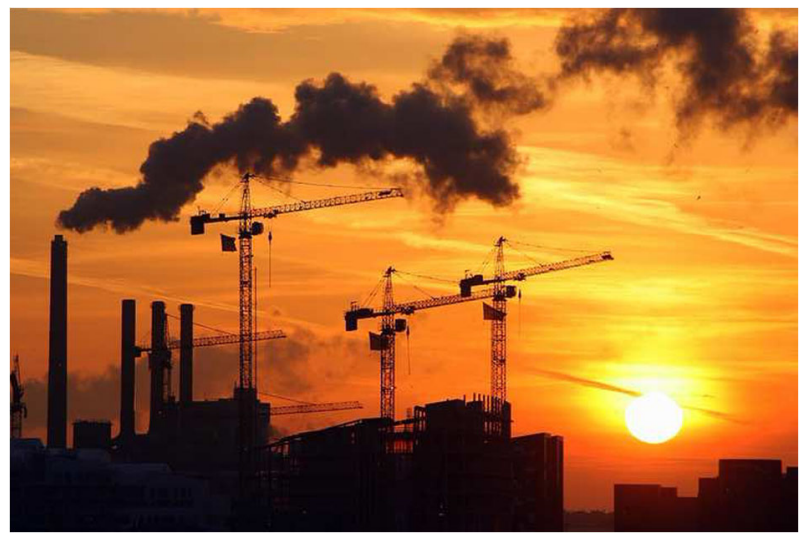

Fig. 5 A typical 'smokestacks' image (note this image is not from the dataset, but is a Creative Commons licenced image used to illustrate the themes discussed). 'Cranes and Chimneys' by Kriffster is licenced under CC BY-NC-ND 2.0

particularly prominent in the Daily Mail, where it reaches over $10 \%$ of coverage in both 2008 and 2009. Such images typically feature many turbines, in both land- and sea-based locations. Whilst images do accompany stories directly about wind power ('Debate Over Wind Power Creates Environmental Rift', New York Times 2006), turbines begin to accompany broader sceptical narratives, where the camera angle of images can often emphasise the size of the turbines and movement of the turbine blades (e.g. 'Greenwash!; A Cambridge don argues that we are being misled by green propaganda', Daily Mail 2008).

Some imagery is noticeable by its absence. The image of the globe from space is an iconic image, drawing on the original visual evoked by the 1972 Apollo 17 space photograph of the globe suspended in space. Although a recognised important and iconic visual of the environmental movement (see Cosgrove 1994), it is uncommon in this climate change visual dataset. It does not appear at all in the New York Times, and only in very low levels in the other four newspapers (between 1 and 2\%). This contrasts with other climate visual work (Rebich-Hespanha et al. 2015), where the globe in space was

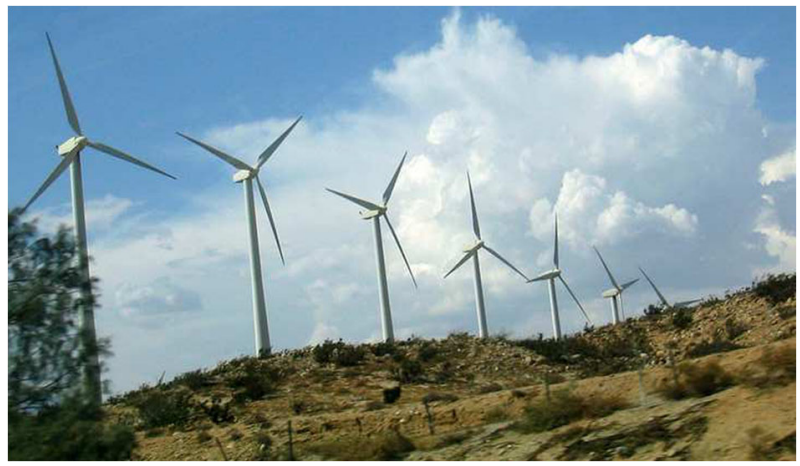

Fig. 6 A typical 'wind turbines' image (note this image is not from the dataset, but is a Creative Commons licenced image used to illustrate the themes discussed). Joe Mud, licenced under CC BY-NC-SA 2.0 
found to be more common ( $6 \%$ of all images; note though that the Hespanha et al. study used less than a third of the imagery examined here $(n=350$, compared with $n=1278)$.

\subsection{Visual framing}

The visual dataset was analysed for visual frames using the framing schema of O'Neill (2013). O'Neill (2013) identified two visual climate change frames: the contested frame, which acted as a divisive device by heightening tension, and by separating the viewer from the narrative by situating climate change as an issue controlled by elites; and the distancing visual frame, which situated climate change as both geographically and psychologically distant to everyday practice and experience, rather than as an issue with impacts, causes and solutions close to home.

Applying the O'Neill (2013) frame schema indicates that between 2001 and 2004, the distancing visual frame was frequently used (Fig. 7). In 2003 and 2004 particularly, there was very little use of the contested visual frame. From 2005 to 2009, the contested frame coverage increased, and the use of the distancing frame decreased. From 2005 to 2008, there was remarkable consistency in the proportion of both frames in visual coverage, despite the rapidly increasing quantity of climate visuals. In 2009, frame use converged, with the contested frame increasing, and the distancing frame decreasing. The framing trends are similar between the USA and UK, although the distancing frame is less common in the USA.

Visual framing appears remarkably resilient to change, even during specific events. For example, reporting around the IPCC's 2007 Fourth Assessment Report produced a peak in visual coverage, but no change in the frames used. The annual COPs and the IPCC's 2001

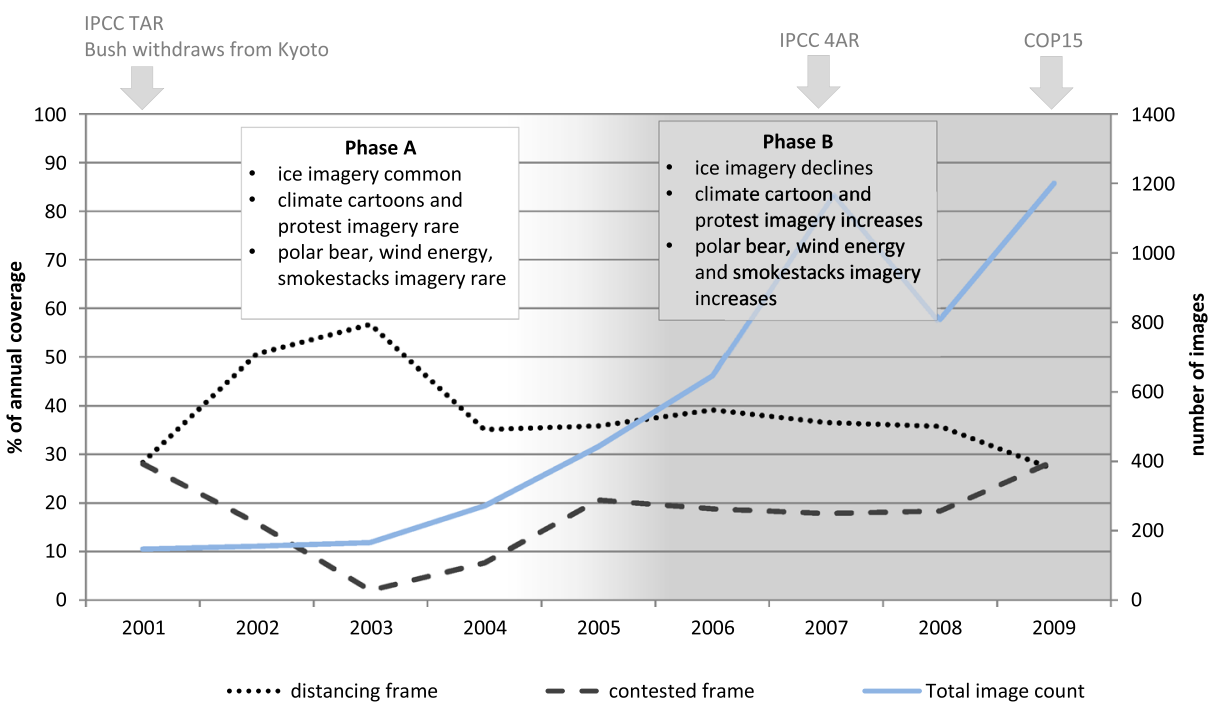

Fig. 7 Change in visual framing over time. The left hand axis shows the mean percentage of visual coverage using the distancing frame (dotted line) and contested frame (dashed line). The right hand axis shows the total count of visuals associated with climate change stories for the five newspapers examined (blue line; comprised of direct and estimated counts, see "Method" section). Two periods of visual coverage are apparent: phase A (white shading) and phase B (grey shading) 
TAR also do not affect visual framing. There are two exceptions. In 2001 (and into 2002), the proportion of contested visual framing was high, and distancing framing was comparatively low. This was the result of coverage from a tumultuous year for climate change policy, as President George W Bush withdrew the USA from the Kyoto Protocol, combined with very low levels of visual coverage overall. In 2009, the proportion of coverage for the two frames converges. Again, climate policy and controversy loomed larger than usual at this point, as COP15 was communicated to journalists as 'the most important meeting since the end of the second world war' (IIED 2009:1). The concurrent Climatic Research Unit email controversy ('Climategate') helped to fuel a significant spike in media attention to climate change (Boykoff et al. 2019).

\section{Discussion}

The analyses above provide evidence of two distinct phases in the visual representations of climate change, with a transition between the two phases at around mid-decade:

Phase A (white shading, Fig. 7) ran between 2001 to 2004. This phase is characterised by low levels of visual coverage (blue line), and little iconic imagery. Climate change is commonly represented through the distancing frame (dotted line), which portrays the issue as a risk distant in time and place to the everyday. This is exemplified by the widespread use of awe-inspiring, vast, people-less polar ice imagery as a visual synecdoche.

Phase B (grey shading, Fig. 7) ran from around 2005 to 2009. In this phase, visual coverage rose rapidly, the contested frame coverage increased (dashed line), and the use of the distancing frame decreased. All newspapers began to feature climate cartoons and climate protest imagery. Visual synecdoches including polar bears, smokestacks and wind energy gained prominence. These synecdoches began to be subverted and parodied in the right-leaning newspapers, particularly in the Daily Mail. This inverted the original reading of these images, changing their message entirely. Imagery of polar bears was subverted from iconic species at risk to object of climate sceptical ridicule; smokestacks changed from visual portrayal of industrial pollution to a satirical metaphor of exaggeration over climate risk; and wind turbines from visual depiction of renewable energy to an icon of green propaganda.

\subsection{What influences newspaper visual coverage?}

There is limited evidence of a spatial geography of image use. Impacts imagery is more common in the UK than the USA, with polar bear imagery in particular being notably rare in US coverage. But overall, image use is remarkably similar between the two nations. This builds on the UK, US and Australian 2010 newspaper visual framing study by O'Neill (2013) and the public engagement with imagery work by O'Neill et al. (2013) to provide further evidence that, at least in these countries, there is a dominant, mainstream visual discourse on climate change. This paper is the first to show that this is also the case over long time periods. This is perhaps influenced partly by the print media looking to international image banks (such as Getty Images) for climate imagery. Such image banks provide a limited set of visual imaginings for search terms such as 'climate change' (Hansen and Machin 2008: see also 
the Climate Visuals project, which seeks to address this issue, Climate Outreach 2019). Empirical research with news organisations is required though to fully understand the drivers of image use and how this may vary cross-culturally (O’Neill and Smith 2014).

Newspaper ideology does influence visual coverage. There is a far greater presence of subverted and parodied synecdoches in the right-leaning newspapers examined. This is in common with the far greater presence of scepticism in the UK and US right-leaning newspapers generally (Painter 2013). Painter posits that sceptical coverage is likely a function of a newspaper's editorial culture, as well as the influence of editors and proprietors. Additionally, newspapers may seek to connect with disenfranchised libertarian and free-market voters who exist on the fringes of mainstream politics through making climate sceptic appeals.

Newspaper type also appears to influence visual coverage. The Daily Mail, the only tabloid newspaper examined, relied particularly heavily on synecdoches such as polar bears and wind energy. It may be that synecdoches are particularly important for the visual culture of tabloid newspapers, where easily-recognised images have to do more of the heavy lifting in a narrative than in a longer-form, more text-heavy broadsheet piece. Reliance on well-worn visual clichés may also be more likely in a tabloid newsroom environment where there are fewer specialist journalists (Boykoff and Mansfield 2008). However, further research examining other tabloid newspapers is required to substantiate this.

\subsection{Why does coverage change mid-decade?}

The change in visual coverage in mid-decade is likely due to a number of interlinked factors. There was a considerable increase in societal and political attention to climate change through the decade. The pattern of coverage is consistent with moving through Downs' issue-attention cycle. At first, there is a baseline low level of interest. Then, multiple events trigger a rise in attention: international climate policy drew media attention through the trials of the Kyoto Protocol: first through the US withdrawal from the Protocol in 2001, then the Protocol's recovery, and its ratification in 2004. The film 'An Inconvenient Truth' launched in 2006. The film's presenter Al Gore, together with the authors of the Fourth Assessment Report of the IPCC, won the 2007 Nobel Peace Prize. As climate change became a more mainstream issue, levels of awareness and support for policy action grew (Capstick et al. 2015). This growing awareness is also evident in text-based analyses of climate discourse; for example, in the growth in textual 'carbon compounds' (carbon finance, carbon footprint, etc.) around this time (Koteyko et al. 2010).

However, with the Stern Report in 2006, there was a clear recognition and realisation of the cost of progress on climate change. Attempts to lead on climate policy, in the UK's Climate Change Act 2008 and in the USA, the 2009 Waxman-Markey Bill, proved divisive. Climate change began to be perceived as a threat to cherished identities. Growing political polarisation, influence from fossil fuel industry interests, and external factors such as the global economic downturn, all contributed to the proliferation of doubt and scepticism about climate change from the latter part of the 2000s on (Whitmarsh 2011; Carmichael et al. 2017; Capstick et al. 2015; Holt and Barkemeyer 2012). This came to a head at the end of the decade as a tranche of emails from the Climatic Research Unit (CRU) were uploaded, unauthorised, onto a Russian server in November 2009 (coinciding with COP15). The resulting controversy over the integrity of climate science triggered a further rise in media attention (see Boykoff et al. 2019) as well as climate visual coverage. The type of visual coverage, as well as the quantity, is also telling here: the growth in 
protest imagery clearly portrays growing societal concern and conflict over climate change; and the rise of climate change cartoons and subverted synecdoches indicates both that audiences have sufficient knowledge of the issue to be able to read satirical elements of an image, and that climate change is an issue growing in complexity.

\section{Conclusion}

This study is the first to use an in-depth longitudinal approach to analyse image use crossculturally. This paper shows how newspaper visuals are actively shaping and reflecting the cultural politics of climate change during 2000-2009, a key decade for climate change engagement. Images associated with articles about climate change in newspapers are not used indiscriminately. Climate change visuals have changed over time, with two distinct phases of visual coverage apparent. Phase A ran from 2001 to 2004 and was characterised by low levels of visual coverage, little iconic imagery, and frequent use of the distancing visual frame. Phase B ran from 2005 to 2009, saw rapidly increasing visual coverage, an increase in use of the contested visual frame, alongside an increase in climate cartoons, protest imagery and visual synecdoches.

The US and UK coverage is remarkably similar. Greater differences are found between newspapers with different ideologies, with right-leaning newspapers relying more on subverted and clichéd visual synecdoches. Paper type also appears to influence imagery, with the tabloid relying much more heavily on synecdoche than the broadsheets. The change in visual coverage is likely due to a number of interlinked factors associated with the rise in doubt and scepticism both in the UK and US media ecosystems and in public perceptions. Further research should look to extend these results beyond the Anglophone nations and legacy media examined to date. In particular, researchers should look to extend climate change image analysis into the visually rich (and often, visually dominant) social media platforms.

This work has implications for public engagement with climate change. It extends the O'Neill (2013) study to show how the contested and distancing visual frames are deeply and historically embedded in the meaning-making of climate change. It is imperative to acknowledge visual framings of climate change, as a frame necessarily will support particular engagements with the issue of climate change, whilst marginalising others. Framing climate change as contested and politicised, and as an issue distant to everyday experience, is unlikely to increase a sense of issue efficacy (O'Neill et al. 2013). Future research should seek to understand if these frames continue to dominate climate media to the present day, and what contemporary visual framing means for wider climate engagement.

It is important to know and understand which visual synecdoches have become embedded in a visual discourse, particularly those which are subject to parody or have become clichéd. This analysis provides empirical evidence of how polar bear imagery is used (or avoided) in order to engage particular audiences. But, it also demonstrates how less prominent synecdoches such as wind energy and smokestacks also carry significance. Whilst audience engagement with climate imagery is a growing research area (see O'Neill 2017 for an overview), understanding of the newsroom and journalistic processes and structures shaping visual representations of climate change is still lacking. Further research could usefully examine these sites of visual production. 
Acknowledgements Many thanks to Phil Johnstone and Chris Manktelow for their diligence and hard work at the British Library archives. Many thanks to several of the anonymous reviewers, as well as the Special Issue editors, who gave some very constructive and insightful feedback. Finally, thanks to the creators of the Creative Commons imagery used to illustrate visual themes arising in this paper, and to Arne Naevra for his 'polar meltdown' image: the generosity of these photographers in sharing their images is gratefully acknowledged.

Funding information This research was partly funded through an Economic and Social Research Council (ESRC) Future Research Leader Grant (ES/K001175/1). The metadata supporting this publication are available from the University of Exeter's institutional repository at https://doi.org/10.24378/exe.1663.

Open Access This article is distributed under the terms of the Creative Commons Attribution 4.0 International License (http:/creativecommons.org/licenses/by/4.0/), which permits unrestricted use, distribution, and reproduction in any medium, provided you give appropriate credit to the original author(s) and the source, provide a link to the Creative Commons license, and indicate if changes were made.

\section{References}

Andrews K et al (2015) World newspaper coverage of climate change or global warming, 2004-2014. Center for Science and Technology Policy Research, University of Colorado, Boulder

Bell P (2001) Content analysis of visual images. In: Van Leeuwen T, Jewitt C (eds) Handbook of visual analysis. Sage, London, pp 10-34

Born D (2018) Bearing witness? Polar bears as icons for climate change communication in National Geographic. Environ Commun 13:649-663

Boykoff M, Boykoff J (2007) Climate change and journalistic norms: a case-study of US mass-media coverage. Geoforum 38:1190-1204

Boykoff MT, Mansfield M (2008) 'Ye Olde hot Aire': reporting on human contributions to climate change in the UK tabloid press. Environ Res Lett 3:024002

Boykoff et al (2019) United Kingdom and United States newspaper coverage of climate change or global warming, 2000-2019. Center for Science and Technology Policy Research, Cooperative Institute for Research in Environmental Sciences, University of Colorado, Media and Climate Change Observatory Data Sets. https://doi.org/10.25810/8196-e820. (05 July 2019)]

Brossard D, Shanahan J, McComas K (2004) Are issue-cycles culturally constructed? A Comparison of French and American Coverage of Global Climate Change. Mass Commun Soc 7:359-377

Capstick S et al (2015) International trends in public perceptions of climate change over the past quarter century. WIREs Clim Change 6:35-61

Carmichael JT, Brulle RJ, Huxster JK (2017) The great divide: understanding the role of media and other drivers of the partisan divide in public concern over climate change in the USA, 2001-2014. Clim Chang 141:599612

Carvalho A, Burgess J (2005) Cultural circuits of climate change in UK broadsheet newspapers, 1985-2003. Risk Anal 25:1457-1469

Climate Outreach (2019) Climate visuals: a climate outreach project. https://climatevisuals.org/. (13 July 2019)

Coleman R (2010) Framing the pictures in our heads. In: D'Angelo P, Kuypers JA (eds) Doing news framing analysis: empirical and theoretical perspectives. Routledge, New York, pp 233-261

Cosgrove D (1994) Contested global visions: one-world, whole-earth and the Apollo space photographs. Ann Assoc Am Geogr 84:270-294

DiFrancesco DA, Young N (2011) Seeing climate change: the visual construction of global warming in Canadian national print media. Cult Geogr 18:517-536

Domke D, Perlmutter D, Spratt M (2002) The prime of our times? An examination of the 'power' of visual images. Journalism 3:131-159

Downs A (1972) Up and down with ecology the 'issue-attention cycle'. Public Interest 28:38-50

Doyle J (2007) Picturing the clima(c)tic: Greenpeace and the representational politics of climate change communication. Sci Cult 16:129-150

Dyer G (1982) Advertising as communication. Routledge, New York

Entman RM (1993) Framing: toward clarification of a fractured paradigm. J Commun 43:51-58

Epstein S (1994) Integration of the cognitive and the psychodynamic unconscious. Am Psychol 21:709-724 
Farrow C (2000) Communicating about climate change: an NGO view. In J. Smith (Ed.) The Daily Globe: Environmental Change, the Public and the Media (London: Earthscan)

Gamson WA, Modigliani A (1989) Media discourse and public-opinion on nuclear power: a constructionist approach. Am J Sociol 95:1-37

Graber DA (1990) Seeing is remembering: how visuals contribute to learning from television news. J Commun 40:134-155

Hall S (1973) The determinations of news photographs. In: Cohen S, Young J (eds) The manufacture of news: deviance, social problems and the mass media. Constable, London

Holt D, Barkemeyer R (2012) Media coverage of sustainable development issues - attention cycles or punctuated equilibrium? Sustain Dev 20:1-17

IIED (2009) COP15 for journalists: a guide to the UN climate change summit. http://pubs.iied.org/pdfs/17074 IIED.pdf. (12 May 2018)

IPCC (2014) Climate change 2014: mitigation of climate change. In: Edenhofer OR et al (eds) Contribution of working group III to the fifth assessment report of the intergovernmental panel on climate change. Cambridge University Press, Cambridge

Joffe H (2008) The power of visual material: persuasion, emotion and identification. Diogenes 55:84-93

Koteyko N, Thelwall M, Nerlich B (2010) From carbon markets to carbon morality: creative compounds as framing devices in online discourses on climate change mitigation. Sci Commun 32:25-54

Leiserowitz A (2006) Climate change risk perception and policy preferences: the role of affect, imagery, and values. Clim Chang 77:45-72

León B, Erviti MC (2013) Science in pictures: visual representation of climate change in Spain's television news. Public Underst Sci 24:183-199

Linder, S.H. (2006) Cashing-in on risk claims: on the for-profit inversion of signifiers for "global warming". Social Semiotics 16:103-132

Lörcher I, Neverla I (2015) The dynamics of issue attention in online communication on climate change. Media Commun 3. https://doi.org/10.17645/mac.v3i1.253

McComas K, Shanahan J (1999) Telling stories about global climate change: measuring the impact of narratives on issue cycles. Commun Res 26:30-57

Messaris P, Abraham L (2001) The role of images in framing news stories. In: Reese SD, Gandy OHJ, Grant AE (eds) Framing public life. Taylor \& Francis, Mahwah

Metag J et al (2016) Perceptions of climate change imagery: evoked salience and self-efficacy in Germany, Switzerland and Austria. Sci Commun 38:197-227

Nerlich B (2019) It's an icon, it's a symbol: It's a polar bear!? Making Science Public blog post. http://blogs. nottingham.ac.uk/makingsciencepublic/2019/04/19/its-an-icon-its-a-symbol-its-a-polar-bear/. (19 June 2019)

Nerlich B, Jaspal R (2014) Images of extreme weather: Symbolising human responses to climate change. Sci Cult 23:253-276

Nisbet MC, Huge M (2006) Attention cycles and frames in the plant biotechology debate: managing power and participation through the press/policy connection. Int J Press/Politics 11:3-40

O'Neill S (2013) Image matters: climate change imagery in US, UK and Australian newspapers. Geoforum 49: 10-19

O’Neill S (2017) Engaging people with climate change imagery. In: The Oxford Encyclopaedia of climate change Communication. Oxford Research Encyclopaedia (Climate Science), Oxford University Press, Oxford. https://doi.org/10.1093/acrefore/9780190228620.013.371

O’Neill S, Smith N (2014) Climate change and visual imagery. WIREs Clim Chang 5:73-87

O’Neill S, Boykoff M, Day S, Niemeyer S (2013) On the use of imagery for climate change engagement. Global Environ Chang 23:413-421

O'Neill S et al (2015) Dominant frames in legacy and social media coverage of the IPCC fifth assessment report. Nat Clim Chang 5:380-385

Painter J (2013) Climate change in the media: reporting risk and uncertainty, Reuters Institute for the Study of journalism Report. University of Oxford, Oxford

Pearce W, Özkula SM, Greene AK, Teeling L, Bansard JS, Omena JJ, Rabello ET (2018) Visual cross-platform analysis: digital methods to research social media images. Inf Commun Soc:1-20

Popp RK, Mendelson AL (2010) ' $\mathrm{X}$ '-ing out enemies: time magazine, visual discourse, and the war in Iraq. Journalism 11:203-221

Rebich-Hespanha S et al (2015) Image themes and frames in US print news stories about climate change. Environ Commun 9:491-519

Remillard C (2011) Picturing environmental risk: the Canadian oil sands and the National Geographic. Int Commun Gaz 73:127-143

Rose G (2012) Visual methodologies: an introduction to the interpretation of visual materials. Sage, London 
Sampei Y, Aoyagi-Usui M (2009) Mass-media coverage, its influence on public awareness of climate-change issues, and implications for Japan's national campaign to reduce greenhouse gas emissions. Glob Environ Chang 19:203-212

Schäfer M, O’Neill S (2017) Frame analysis in climate change communication. The Oxford Encyclopaedia of climate change communication. Oxford Research Encyclopaedia (Climate Science), Oxford University Press, Oxford

Schäfer M, Ivanova A, Schmidt A (2014) What drives media attention for climate change? Explaining issue attention of Australian, German and Indian print media from 1996 to 2010. Int Commun Gaz 76:152-176

Schmidt A, Ivanova A, Schäfer MS (2013) Media attention for climate change around the world: a comparative analysis of newspaper coverage in 27 countries. Global Environ Chang 23:1233-1248

Singh SP, Swanson M (2017) How issue frames shape beliefs about the importance of climate change policy across ideological and partisan groups. PLoS One 12:e0181401

Smith J (2017) Demanding stories: television coverage of sustainability, climate change and material demand. Phil Trans R Soc A375:20160375

Smith N, Joffe H (2009) Climate change in the British press: the role of the visual. J Risk Res 12:647-663

Urry J (1992) The tourist gaze "revisited". Am Behav Sci 36:172-186

Whitmarsh L (2011) Scepticism and uncertainty about climate change: dimensions, determinants and change over time. Glob Environ Chang 21:690-700.s

Wozniak A, Lück J, Wessler H (2015) Frames, Stories, and images: the advantages of a multimodal approach in comparative media content research on climate change. Environ Commun 9:469-490

Publisher's note Springer Nature remains neutral with regard to jurisdictional claims in published maps and institutional affiliations. 